\title{
Tribal Community Visit to Malaria-Endemic Areas Can Pose Risk to Car Nicobar Island: Deterrent for Malaria Elimination
}

\author{
Zahid Ali Khan', Ittoop Pulikkottil Sunish ${ }^{1 *}$ \\ ${ }^{1}$ Division of Medical Entomology, Regional Medical Research Centre-ICMR, Dollygunj, Port Blair, Andaman and Nicobar \\ Islands 744103, India
}

Corresponding Author: Ittoop Pulikkottil Sunish, PhD, Division of Medical Entomology, Regional Medical Research CentreICMR, Post Bag No. 13, Dollygunj, Port Blair, Andaman and Nicobar Islands 744103, India. Tel: +95-31954301, Email: sunish67@gmail.com

Received November 15, 2018; Accepted February 16, 2019; Online Published March 4, 2019

\begin{abstract}
Introduction: In the past 10 years, a declining trend was seen in the annual parasite incidence (API) of malaria in the Car Nicobar Island. For the past few years, the API in the island has been below one. Car Nicobar Island is struggling with malaria cases reported to have been brought from other, malaria-endemic islands.

Methods: The movements of people were monitored by door-to-door visits during early morning hours, and the frequency of their movements to different islands (malarious and non-malarious areas) were monitored.

Results: A larger number of villagers visited non-malarious areas (OS-O) than malarious areas (OS-N). The maximum number of people was found out of station during the month of June. Thirty-seven percent of people were out of the station to non-malarious areas, while only $6 \%$ were out of the station to islands endemic for malaria. In the latter category, the majority of those who left the village were in the age groups of 16-30 years and 31-45 years. Even though fewer villagers visited malaria-endemic areas, their visits can pose a threat of malaria transmission, in view of the prevalence of local anopheline vectors.

Conclusion: Understanding people's movement patterns to and from high malaria-transmission areas is important to designing strategic evidence-based control plans. In Car Nicobar, the main transport facilities within the inter-islands are ship and helicopter services. Hence, post-arrival medical examinations should be made mandatory to prevent the introduction of malaria parasites into the island.

Keywords: Malaria, Travel, Islands
\end{abstract}

Citation: Khan ZA, Sunish IP. Tribal Community visit to malaria-endemic areas can pose risk to Car Nicobar Island: deterrent for malaria elimination. Int JTravel Med Glob Health. 2019;7(1):33-37. doi:10.15171/ijtmgh.2019.07.

\section{Introduction}

The movement of people in a variety of forms and on various scales plays a significant role in the equation of malaria and people in parasite vectors, who contribute to the transmission of malaria by exposing other people to the risk of infection and obscuring its control. Health sectors worldwide have always recognized the movement of people as a significant means of infectious pathogen transmission. ${ }^{1}$ Peoples' movement has historically stood as a great challenge to the control and elimination of malaria. ${ }^{2}$ The failure of global malaria eradication programs has been attributed mainly to human population movement (HPM) as well as drug resistance..$^{3,4}$ The introduced/imported cases contribute a great threat of outburst initiation, epidemics, or increasing indigenous transmission levels in highly accessible areas. ${ }^{5}$ Understanding the transmission route of malaria parasites, principally through the travel of infected persons, is vital for efficacious intervention strategies across the full range of transmission intensities. ${ }^{6}$ Therefore, it is important to quantify the peoples' movement while choosing appropriate control strategies and developing a comprehensive elimination feasibility assessment. $^{7}$

Malaria is one of the most important vector-borne diseases in the Andaman and Nicobar archipelago, but for the past few decades, a decline in malaria incidence rate has been observed. A total of 23 anopheline species have been reported in these islands. ${ }^{8}$ Of these, Anopheles sundaicus cytotype 'D', which breeds in both fresh and brackish water, is the incriminated malaria vector. ${ }^{9-11}$ This principal vector is primarily zoophagic (prefers to feed on animals), exophilic (prefers to rest

Copyright $(0) 2019$ The Author(s). This is an open-access article distributed under the terms of the Creative Commons Attribution License (http:// creativecommons.org/licenses/by/4.0), which permits unrestricted use, distribution, and reproduction in any medium, provided the original work is properly cited. 
outdoors), and exophagic (prefers to feed outdoors). ${ }^{12,13}$ The 2004 tsunami caused severe devastation in these islands, and the number of malaria cases increased due to the proliferation of malaria vector species by the formation of more breeding habitats. ${ }^{14}$ Among the 3 districts of the Andaman and Nicobar Islands, the Nicobar district was highly affected by the tsunami. Laborers who came from mainland India for rehabilitation work were affected by malaria. Their movement to different islands for construction purposes increased the risk of malaria transmission. However, during the past few years, a drastic reduction in cases has been observed in the archipelago, and the API (annual parasite incidence) declined from 11.9 in 2011 to 0.87 in 2017.

Car Nicobar is one of the 3 tehsils of the Nicobar district. Malaria was widespread in the island subsequent to the tsunami disaster of 2004. However, a declining trend was observed in API for the years between 2011 and 2017, ranging from 4.4 to $0.20 .{ }^{15}$ In the other 2 tehsils of the Nicobar district, endemicity is still high with an API greater than 5. Vector control intervention is being implemented on the Car Nicobar Island and has been found to be effective, in contrast with the other islands of the Nicobar district. The introduction of the larvivorous fish Gambusia affinis into the breeding habitats of the island is one reason for the declining trend of malaria. ${ }^{16}$ Nonetheless, this island has struggled for the past few years with malaria likely brought from other, malaria endemic islands of the Nicobar district. One of the major risk factors for malaria infection is the lack of community awareness about malaria transmission and prevention. ${ }^{17}$ Being on the verge of eliminating malaria, having an API less than one for the past few years, a quantifiable determination of peoples' movement is important to resolving how best to devise intervention strategies. ${ }^{18}$ In view of these factors, the frequency of peoples' movement to other islands (malaria endemic and non-endemic) and vice versa was investigated.

\section{Methods}

\section{Study Site}

Car Nicobar (located at $9.16^{\circ} \mathrm{N}, 92.75^{\circ} \mathrm{E}$ ) spans over $127 \mathrm{~km}^{2}$ of mostly flat terrain, except for small hilly areas in the interior. The island has a human population of 17800 , as per the 2011 census, and is inhabited by the native aboriginal 'Nicobari' tribal community which belongs to the mongoloid race. The current study was undertaken in 2 villages, viz., Kakana and Kinmai, for a period of one year (May 2016 to April 2017). Total population (' $\mathrm{n}$ ' = number of people) of the study area was 1400 , and the majority of the villagers were farmers. Coconut plantation is the main source of income. The 2 villages were selected based on the malaria cases reported in the past few years. Weekly ship service and daily helicopter service, subject to weather conditions, are the only means of transportation for this island.

\section{Study Design}

The movement of people from the 2 selected villages to outstations was monitored longitudinally on a monthly basis from May 2016 to April 2017. Data of household members was tabulated in a registry, and those working/residing out of station for a sufficiently long period were excluded from the survey. The movement of people to outstations was monitored in monthly door-to-door visits in both villages during early morning hours by enquiring the presence and absence of household members. Those people who were not available in the household for the survey but were present on the island were marked as absent, and those available in the household were marked as present. People moved to and from different islands, and these movements did not involve a permanent change of residence. These movements included visits to relatives, attendance at ceremonies, treatment-seeking in hospitals, etc. and resulted in a return to the island. Along the temporal dimension, those persons found out of station during the sampling time were classified as "OS-O" for those out of station to non-malarious areas (like Port Blair) or "OS$N$ " for those out of station to malarious areas (mainly to the Nicobar group of islands). The total population of the study area was categorized into different age groups to depict which particular age group had the highest frequency of movements. The study population was kept constant and those individuals who were born or expired during the survey were excluded from the analysis. Guests who visited Car Nicobar Island from malaria-endemic areas (other Nicobar Islands) were also recorded during the study period.

\section{Statistical Analysis}

The data was entered in Microsoft Excel worksheet and analyzed using Epi Info, version 20.0. Descriptive statistics (frequencies, means, standard errors, and standard deviations) were used to tabulate and describe the data. The chi-square test was used to determine the level of significance of variables. A $P$ value of $<0.05$ indicated statistical significance.

\section{Results}

The total population of the 2 studied villages $(n=1400)$ was categorized into different age groups: $<5,6-15,16-30,31-45$, 46-60, and >60 (Table 1). A non-significant difference was observed among different age groups of males and females in the 2 villages $\left(\chi^{2}=4.11 ; P=0.533\right)$. The majority of the people were present on the island during the survey period, with a maximum number of 1385 (98.9\%) during the month of December. Among the total population, $54.28 \%$ were male and $45.91 \%$ were female.

\section{Monitoring Out-of-Station Individuals}

In the OS-O category (out of station to non-endemic area), the movement of the highest number of people was observed in the month of June $(6.07 \% \pm$ SE 0.013$)$, and gradually

\begin{tabular}{lccc}
\multicolumn{4}{l}{ Table 1. Age Group Representation of Population Categorized as Male and Female } \\
\hline Age group (y) & Male, No. (\%) & Female, No. (\%) & $\boldsymbol{P}$ Value \\
\hline$<5$ & $82(10.79)$ & $60(9.4)$ & 0.064 \\
$6-15$ & $108(14.21)$ & $81(12.7)$ & 0.049 \\
$16-30$ & $217(28.55)$ & $199(31.1)$ & 0.377 \\
$31-45$ & $191(25.13)$ & $178(27.8)$ & 0.498 \\
$46-60$ & $121(15.92)$ & $88(13.8)$ & 0.022 \\
$>60$ & $41(5.39)$ & $34(5.3)$ & 0.418 \\
Total & $760(100)$ & $640(100)$ & \\
\hline
\end{tabular}


declined from July $(4.57 \% \pm$ SE 0.379$)$ to December $(1.07 \% \pm$ SE 0.266), when fewer people were out of station (Figure 1). A comparison of the movement of people from the 2 villages determined that more people were out of station (OS-O) from Kakana (20.21\%) than from Kinmai (17.07\%).

In the second category (OS-N: out of station to malaria endemic area), More people were OS-N (out of station to malaria endemic area) during the month of June $(1.29 \% \pm$ SE 0.673$)$. This number gradually declined in July $(1.0 \% \pm \mathrm{SE}$ 0.474), and in the month of December no record of people visiting endemic areas was reported (Figure 2). Comparing the 2 villages under study, more people visited malaria endemic areas from Kinmai (7.44\%) during the whole year. In the OS-N category, the majority of people were found out of station for a period of one month. In Kakana and Kinmai, $0.97 \%$ and $1.04 \%$, respectively, were reported OS-N for one month only. The chi-square test did not show any significant difference between the movement of people outstation to malarious areas (OS-N) and non-malarious areas (OS-O) among the different months $\left(\chi^{2}=13.66 ; d f=11 ; P=0.251\right)$.

Analysis of Age Groups in OS-O and OS-N Categories In both categories (OS-O and OS-N), the highest number of people were reported outstation in the month of June. The movement rates of people in the OS-O category (Figure 3) were highest in the 16-30 years age group $(n=294)$ and lower in the age groups $<5$ years and $>60$ years throughout the year.

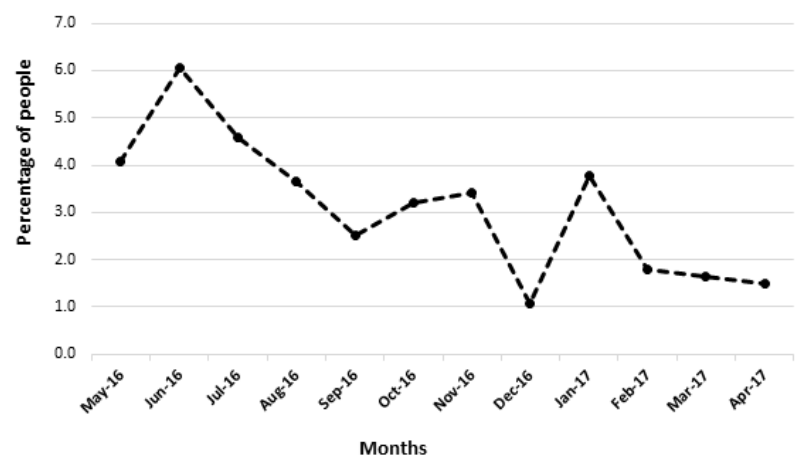

Figure 1. Monthly Movement of People (in Percentages) to Non-malarious Areas (OS-O) for a Period of 1 Year.

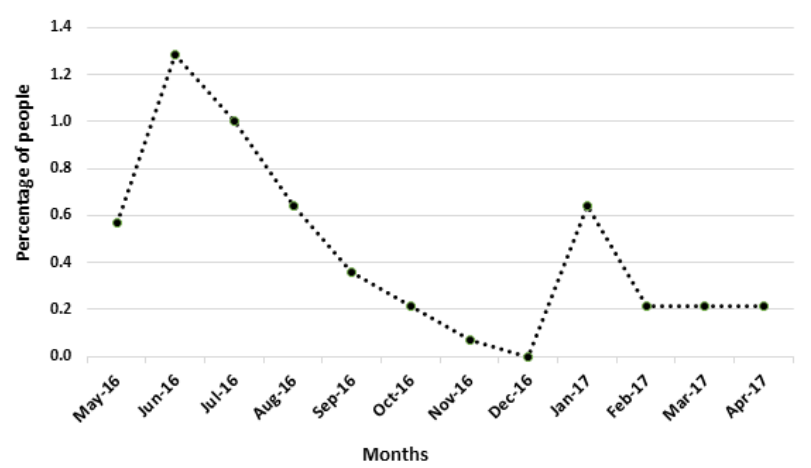

Figure 2. Monthly Movement of People (in Percentages) to Malarious Areas (OSN) for a Period of 1 Year.
Most of the people who were reported outstation in the OS-N category (Figure 4) belonged to the age groups of 31 45 years $(n=41)$ and $16-30$ years $(n=33)$. No individuals were reported outstation (OS-N) in the age group of $<5$ years, 6-15 years, or $>60$ years during the whole year. There was a statistically significant difference among the different age groups in the OS-O and OS-N categories $\left(\chi^{2}=13.98\right.$; $P=0.015)$.

A total of 139 guests visited the 2 villages during the whole year. More guests were found in the month of December $(29+$ SE 12.50) and a much lower number of guests were recorded in the month of May ( $2 \pm$ SE 1.41). A total of 37 guests were recorded visiting this island from other Nicobar Islands (malaria endemic areas) during the whole year.

\section{Discussion}

Travel and transport contribute greatly to the dissemination of various pathogens around the globe. It is reasonable to believe that the temporal and spatial patterns of people's movements is a significant factor in the epidemiology of vector-borne diseases as well as the resurgence of malaria. ${ }^{4}$ The villagers in the present study were reported to travel to both malaria endemic and non-endemic zones. The local transmission of malaria has not been reported in Car Nicobar for the past few years, as evident from the vector-infection parameters. However, malaria cases were found among the people who had recently visited malaria-endemic areas/islands (Nicobar).

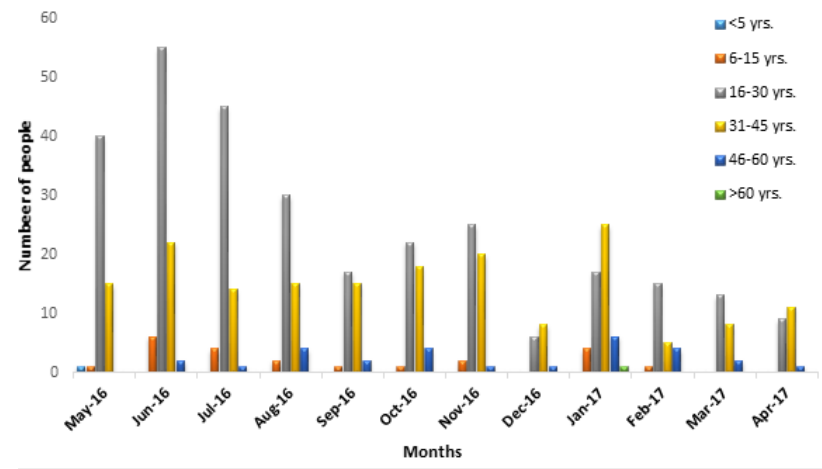

Figure 3. Number of People Who Went out of Station to Non-malarious Areas (OS-O) Categorized by Different Age Groups.

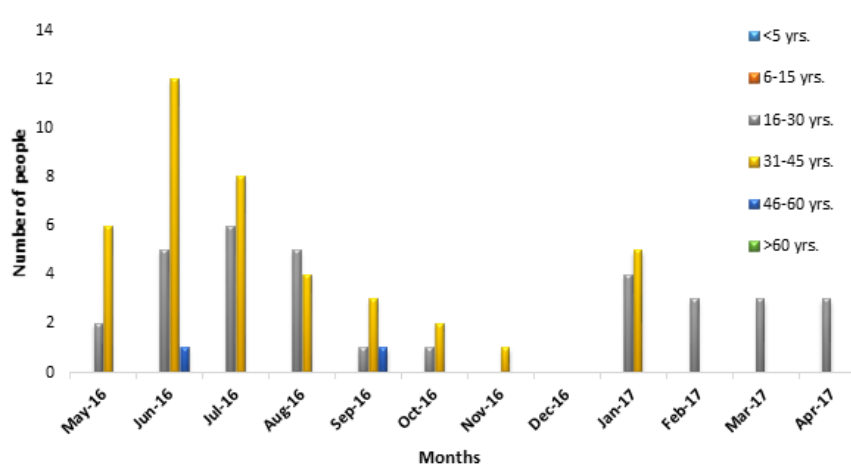

Figure 4. Number of People Visiting Malarious Areas (OS-N) Categorized Into Different Age Groups. 
Malaria parasites brought by visitors and travelers carry the risk of recommencing local transmission of the disease in areas where anopheline vector mosquitoes persist. ${ }^{19}$ The island of Car Nicobar has transport facilities to other islands (endemic and non-endemic) through a weekly ship service. During the present study, people's movement was observed to be more toward non-endemic zones than to malaria endemic areas. Due to people's movement from malaria endemic areas to non-immune zones, an understanding of the bionomics of the local malaria vector is essential. A. sundaicus, the incriminated malaria vector in the Andaman and Nicobar islands, has been found to be prevalent in Car Nicobar (personal communication). Humans travel much larger distances than mosquitoes; hence, human movement plays a significant role in parasite dissemination. ${ }^{20}$ Car Nicobar is at the verge of eliminating malaria, but it is still struggling with cases reportedly being brought from other islands. Malaria elimination cannot be achieved until effective interruption strategies are in place. As reported in the few countries that are nearing elimination, a high proportion of cases are found among migrant and mobile populations living in hard-toreach areas, suggesting that cases imported by visitors and migrants must be identified and treated rapidly. ${ }^{19}$

The majority of the villagers in the present study are cultivators and spend most of their time working in forest areas. Some of them even spend weeks in the forest by staying in temporary shelters and, after completing cultivation, return to their respective villages. The highest number of people were found to be present on the island in the month of December. As this month coincides with the Christian festival of Christmas, and being that Car Nicobar is a Christian community, the residents working outside the island visit their hometown to celebrate. Thus, this period can be regarded as the best time period for implementing IEC (information, education, and communication) campaigns and other awareness programs among the villagers. Over 130 guests were found to be visiting this island during one year, and the maximum number of guests was recorded in December. Among them, 37 were from the southern region of the Nicobar Islands where malaria is endemic. Because this vector is prevalent on this island, there is the risk of malaria transmission, as human movement has been reported to be the cause of the spread of drug-resistant malaria parasites in Southeast Asia. ${ }^{21}$ Each untreated malaria infection brought by a resident or a visitor would be counted the same. Movements to high malaria risk areas not only lead to individual infection, but on return also contribute to local transmission due to the prevalence of the vector, as reported in studies from Columbia. ${ }^{22,23}$ A. sundaicus is the lone malaria vector in Car Nicobar. Being a strong flier, it has a flight range of $9.6 \mathrm{~km} .{ }^{24}$ The chances of local transmission are greater as the area of the island is a mere $126 \mathrm{~km}^{2}$.

Adults (31-45 years) and youths (16-30 years) were outstation to malaria-endemic areas throughout the year. These villagers were reported to be traveling to malarious areas to visit friends and relatives and to attend marriages or other functions. These people stay with local family members and may possibly bump into sub-optimal housing situations; thus, the risk of malaria is increased. ${ }^{25,26}$ The

\section{Research Highlights}

\section{What Is Already Known?}

A declining trend was observed in the annual parasite incidence (API), ranging from 4.4 in 2011 to 0.20 in 2017. 2. Introduction of the larvivorous fish Gambusia affinis into the breeding habitats of the island was one reason for the decline in the number of malaria cases.

\section{What This Study Adds?}

1. For the past few years, Car Nicobar island has been struggling with malaria cases reported to have been brought from other islands of the Nicobar district which are malaria endemic.

2. A low number of tribals were found to have visited malaria endemic areas. However, the risk of malaria transmission exists on the island due to the prevailing vector population.

movement patterns of people vary significantly in spatial and temporal scales, stimuli for travel, and socioeconomic and demographic characteristics of travelers. ${ }^{27}$ Short-term movements toward endemic areas were seen more, as most people were seen outstation to Nicobar Islands for a period of one month. These short-term movements are expected to be more appropriate amid various transmission zones by assessing the number of imported infections. ${ }^{18}$ Therefore, the implications of people's movement for malaria can be better understood when more specific spatio-temporal dimensions are given. ${ }^{28}$ The declining trend in local transmission needs to be refocused on the malaria parasites being brought by visitors. Regular monitoring of malaria cases brought by villagers from endemic areas needs to be strengthened and treated appropriately in order to achieve the goal of malaria elimination.

\section{Conclusion}

Due to the multidimensional interaction between people's movement and malaria, a multi-sectorial approach for malaria control and elimination is necessary. Results of the present study can be extended to the other islands of Andaman and Nicobar in order to plan effective malaria control strategies. After the API was reduced to less than one in Car Nicobar, preventing a resurgence of infection is crucial. Parasite transmission routes can be checked by carrying out a sensitivity investigation on the number of exogenous infections transported by inhabitants and visitors. Understanding people's movement patterns to and from high transmission regions is important for designing strategic evidence-based control plans. In Car Nicobar, the main transport facilities within the inter-islands are ship and helicopter services. Hence, post-arrival medical examinations should be made mandatory to prevent the introduction of the parasite onto the island. This can be achieved with close monitoring by the local tribal council and village heads and the Andaman and Nicobar administration, and it will facilitate the achievement of malaria elimination at a faster pace. 


\section{Authors' Contributions}

ZAK designed, conceived and led the research abetted with ideas, methodological and editorial input of IPS. The analysis of the data and manuscript writing was performed by ZAK and IPS contributed to the analyses. The study design, results, figures and manuscript revision was discussed and approved by all authors.

\section{Conflict of Interest Disclosures}

There is no conflict of interest.

\section{Ethical Approval}

Not applicable.

\section{Funding/Support}

None.

\section{Acknowledgments}

The current study is part of the $\mathrm{PhD}$ thesis of the principal author. The authors wish to thank the Director of ICMRRMRC, Port Blair, for providing the facilities to carry out the study. The co-operation rendered by the Tribal Council, the village headman, and the community of Car Nicobar Island is also gratefully acknowledged.

\section{References}

1. Gushulak B, Weekers J, Macpherson D. Migrants and emerging public health issues in a globalized world: threats, risks and challenges, an evidence-based framework. Emerg Health Threats J. 2009;2:e10. doi:10.3134/ehtj.09.010.

2. Guyant $\mathrm{P}$, Canavati $\mathrm{SE}$, Chea N, et al. Malaria and the mobile and migrant population in Cambodia: a population movement framework to inform strategies for malaria control and elimination. Malar J. 2015;14:252. doi:10.1186/s12936-015-0773-5.

3. Bruce-Chwatt LJ. Malaria and its control: present situation and future prospects. Annu Rev Public Health. 1987;8:75-110. doi:10.1146/annurev.pu.08.050187.000451.

4. Martens P, Hall L. Malaria on the move: human population movement and malaria transmission. Emerg Infect Dis. 2000;6(2):103-109. doi:10.3201/eid0602.000202.

5. World Health Organization (WHO). Malaria elimination: a field manual for low and moderate endemic countries. Geneva: WHO; 2007.

6. Pindolia DK, Garcia AJ, Huang Z, et al. The demographics of human and malaria movement and migration patterns in East Africa. Malar J. 2013;12:397. doi:10.1186/1475-2875-12-397.

7. Feachem RGA, Phillips AA, Targett GA. Shrinking the malaria map: a prospectus on malaria elimination. San Francisco: The Global Health Group, Global Health Sciences, University of California; 2009.

8. Nagpal BN, Sharma VP. Mosquitoes of Andaman Islands. Indian J Malariol. 1983;20:7-13.

9. Dusfour I, Michaux JR, Harbach RE, Manguin S. Speciation and phylogeography of the Southeast Asian Anopheles sundaicus complex. Infect Genet Evol. 2007;7(4):484-493. doi:10.1016/j. meegid.2007.02.003.

10. Nanda N, Das MK, Wattal S, Adak T, Subbarao SK. Cytogenetic
Characterization of Anopheles sundaicus (Diptera: Culicidae) Population from Car Nicobar Island, India. Ann Entomol Soc Am. 2004;97(1):171-176. doi:10.1603/0013-8746(2004)097[0171:CC OASD]2.0.CO;2.

11. Das MK, Nagpal BN, Sharma VP. Mosquito fauna and breeding habitats of anophelines in Car Nicobar Island, India. Indian J Malariol. 1998;35(4):197-205.

12. Kumari R, Sharma VP. Resting and biting habits of Anopheles sundaicus in Car Nicobar Island. Indian J Malariol. 1994;31(3):103114.

13. Kumari R, Joshi H, Giri A, Sharma VP. Feeding preferences of Anopheles sundaicus in Car Nicobar Island. Indian J Malariol. 1993;30(4):201-206.

14. Krishnamoorthy K, Jambulingam P, Natarajan R, Shriram AN, Das PK, Sehgal SC. Altered environment and risk of malaria outbreak in South Andaman, Andaman \& Nicobar Islands, India affected by tsunami disaster. Malar J. 2005;4:32. doi:10.1186/1475-28754-30.

15. Directorate of health services (DHS). Andaman and Nicobar Islands. 2017.

16. Manimunda SP, Shah WA, Shriram AN, et al. Malaria in Car Nicobar Island in the aftermath of the tsunami: some observations. Natl Med J India. 2009;22(4):217-218.

17. Bui HM, Clements AC, Nguyen QT, et al. Social and environmental determinants of malaria in space and time in Viet Nam. Int J Parasitol. 2011;41(1):109-116. doi:10.1016/j.ijpara.2010.08.005.

18. Wesolowski A, Eagle N, Tatem AJ, et al. Quantifying the impact of human mobility on malaria. Science. 2012;338(6104):267-270. doi:10.1126/science.1223467.

19. World Health Organization (WHO). Eliminating malaria. https:// www.who.int/malaria/en/.

20. Lynch C, Roper $\mathrm{C}$. The transit phase of migration: circulation of malaria and its multidrug-resistant forms in Africa. PLoS Med. 2011;8(5):e1001040. doi:10.1371/journal.pmed.1001040.

21. Dondorp AM, Fairhurst RM, Slutsker L, et al. The threat of artemisinin-resistant malaria. N Engl J Med. 2011;365(12):10731075. doi:10.1056/NEJMp1108322.

22. Osorio L, Todd J, Bradley DJ. Travel histories as risk factors in the analysis of urban malaria in Colombia. Am J Trop Med Hyg. 2004;71(4):380-386. doi:10.4269/ajtmh.2004.71.380.

23. Ochoa J, Osorio L. [Epidemiology of urban malaria in Quibdo, Choco]. Biomedica. 2006;26(2):278-285. doi:10.7705/biomedica. v26i2.1417.

24. Covell G, Singh P. Malaria in the Coastal Belt of Orissa. J Malar Inst India.1942;4(4):457-593.

25. Wagner KS, Lawrence J, Anderson L, et al. Migrant health and infectious diseases in the UK: findings from the last 10 years of surveillance. J Public Health (Oxf). 2014;36(1):28-35. doi:10.1093/ pubmed/fdt021.

26. Barnett ED, MacPherson DW, Stauffer WM, et al. The visiting friends or relatives traveler in the 21st century: time for a new definition. J Travel Med. 2010;17(3):163-170. doi:10.1111/j.17088305.2010.00411.x.

27. Morrison PA, Bryan TM, Swanson DA. Internal Migration and Short-Distance Mobility. In: Siegel JS, Swanson DA, eds. The Methods and Materials of Demography. Elsevier Academic Press; 2004. doi:10.1016/B978-012641955-9/50053-9.

28. Stoddard ST, Morrison AC, Vazquez-Prokopec GM, et al. The role of human movement in the transmission of vector-borne pathogens. PLoS Negl Trop Dis. 2009;3(7):e481. doi:10.1371/ journal.pntd.0000481. 